\title{
Second Language Acquisition of Progressive Aspect of Stative and Achievement Verbs in English
}

\author{
Mohammad Falhasiri \\ Department of English Language, University of Isfahan, Isfahan, Iran \\ Email: Falhasiri@yahoo.com \\ Manijeh Youhanaee \\ Department of English Language, University of Isfahan, Isfahan, Iran \\ Email: Youhanaee_m@hotmail.com \\ Hossein Barati \\ Department of English Language, University of Isfahan, Isfahan, Iran \\ Email: H.barati@gmail.com
}

\begin{abstract}
The progressive aspect in stative verbs, due to their semantic, and in achievement verbs, due to their occurrence at a single moment, is widely recognized as unacceptable and uncommon. This paper reports on the judgment of EFL learners of English as well as native speakers on compatibility of progressive aspect with these two verb categories. To the mentioned aim, 70 EFL learners of English, assigned to four groups of elementary, low intermediate, high intermediate and advanced learners, as well as 10 native speakers were chosen as the participants of the present study. A test of grammatically judgment of progressive form in state and achievement verbs in which the participants were given some sentences containing state and achievement verbs in progressive form along with some fillers was devised and the participants were asked to evaluate if they were grammatically acceptable or not. The results showed that the majority of native speakers judged progressive use in both state and achievement verbs as acceptable while advanced learners, with a wide margin, considered progressive forms unacceptable. When the results of all groups were analyzed, it was concluded that the higher the level of participants was, the more they accepted the progressive form as unacceptable.
\end{abstract}

Index Terms - state verb, achievement verb, aspect, progressive aspect

\section{INTRODUCTION}

A. Tense and Aspect

Comrie (1976) differentiates between tense and aspect explaining that "Tense relates the moment of the situation in relation to some other time, usually to the moment of speaking." Three kinds of tense (i.e., past, present and future) are commonly observed in most languages. Aspect, however, is the way events evolve in time i.e., whether or not an event is ongoing or has reached the culminating point (Comrie, 1976; Chung \& Timberlake, 1985; Smith, 1991).

Gabriel (2005) states that Zeno Vendler (1967) was the first person who tried to establish four distinct categories of English verbs according to aspectual differences with regard to their restrictions on time adverbials, tenses, and logical entailments (Dowty, 1979). Situation aspect (aspect in verbs/ verb phrases) classifies verbs and verb predicates into four classes based on their semantic properties: states, activities, accomplishments and achievements. States (or statives) are homogeneous and static and have no internal structure which changes over time. Activities are homogeneous, ongoing, dynamic situations with no inherent goal (i.e., atelic). Accomplishments involve an activity which progresses towards an inherent culmination point in time, after which the event can no longer continue (i.e., telic). Achievements have an inherent culmination point, in which the duration of time leading up to this point is instantaneous (i.e., telic). Dowty (1979) further defined Vendler's classification and therefore, the classification of verbs is also known as the Vendler-Dowty classification. Each verb class has internal characteristics helping us differentiate verbs and categorize them into different classifications. These internal characteristics are indicated by contrasting features: $[+/-$ static], [+/telic] and [+/- duration] (Smith, 1991). Table 1 shows the schematized situation types categorized by these three features. 
TABLE 1.

FEATURES OF SITUATION TYPES

\begin{tabular}{|l|l|l|l|}
\hline Situations & Static & Durative & Telic \\
\hline States & {$[+]$} & {$[+]$} & n/a \\
\hline Activities & {$[-]$} & {$[+]$} & {$[-]$} \\
\hline Accomplishments & {$[-]$} & {$[+]$} & {$[+]$} \\
\hline Achievements & {$[-]$} & {$[-]$} & {$[+]$} \\
\hline
\end{tabular}

As can be seen in Table 1, [+/- static] divides situation types into two classes: states and events. States are static and they consist of an undifferentiated moment with no endpoint, whereas events are dynamic and involve agency, activity and change (Smith, 1991). [+/- durative] classifies the event types as either durative [+ durative] or instantaneous [durative]. Since achievements are instantaneous events, they are categorized as [Indurative] whereas the others are classified as [+ durative] (i.e., states, activities and accomplishments).

The feature [+/- telic] is only relevant to events, but not to states, since events have an internal structure which would make a distinction between either telic or atelic (telic events have inherent goals and ending point, whereas atelic events do not). Activities which do not have inherent endpoints are atelic, whereas accomplishments and achievements are telic as they have intrinsic endpoints.

Now consider the examples in (1).

(1) a. Ken is finding an answer.

b. *Ken is knowing an answer.

These examples show the syntactic difference between the verbs. In particular, the verb in example (1)a. find can combine with the progressive form -ing, entailing an event in progress, whereas the verb in example (1)b. know cannot appear with the progressive form. These examples show that it is not the case that all verbs can be compatible with the progressive marker -ing. (These examples are mentioned because this study tries to evaluate students' grasp of this issue). Take examples in number (2) into consideration.

(2) a. A train was arriving at the station.

b. David was running.

Examples in (2) demonstrate the difference in semantic entailment of the verbs. For example, (2) a. A train was arriving at the station does not imply A train arrived at the station. However, (2) b David was running implies David ran. It can be concluded that some verbs show different semantic implication.

According to Smith, there is variation across languages at the levels of grammatical and VP aspect and also in the interaction between the two levels. For example, at the level of VP aspect, a certain verb may be a stative in one language and an activity in another. This is true of the verb that means 'understand' in English and Farsi. Understand is classified as a stative in English because it is somewhat awkward in progressive form, but in Farsi the verb "Fahmidan" can be used in progressive form.

The Vendler classification, developed further by Dowty (1979), is presented with examples in Table 2. (Modified version of table in Dowty, 1979, p.54).

TABLE 2.

DOWTY'S CLASSIFICATION

\begin{tabular}{|l|l|l|l|}
\hline States & Activities & Accomplishments & Achievements \\
\hline Know & Run & paint a picture & recognize (NP) \\
\hline Believe & Walk & make a chair & find (NP) \\
\hline Have & Swim & draw a circle & reach (NP) \\
\hline Love & push a cart & deliver a sermon & Die \\
\hline Desire & Drive a car & Recover from illness & Spot \\
\hline
\end{tabular}

Vendler distinguishes the four classes on the basis of two main properties: First he groups state and achievements together because he observed that neither was generally compatible with the progressive (the two categories considered in this study); activities and accomplishments on the other hand are compatible. Rothstein (2004) refers to this property with the features $[ \pm$ stages]. Verkuyl (1993) refers to this property as [ \pm process]. Despite the fact that states and achievements do not have a process component, activities and accomplishments do. This is because states have no internal structure and achievements are said to occur instantaneously (Cited in Gabriel, 2005).

Table.3 taken from Rothstein $(2004$, p. 12) summarizes some of the main properties that delineate the Vendler verb classes.

TABLE 3.

PROPERTIES OF VERB CLASSES

\begin{tabular}{|l|l|l|}
\hline & {$[ \pm$ stages $]$} & {$[ \pm$ telic $]$} \\
\hline States & - & - \\
\hline Activities & + & - \\
\hline Accomplishments & + & + \\
\hline Achievements & - & + \\
\hline
\end{tabular}


Vendler offers aspectual verb categories according to two kinds of criteria, continuousness and participation of endpoints. The following table shows the summary of Vendler's aspectual verb classification in English. (Vendler 1967; Dowty, 1979, p. 54):

TABLE 4.

VENDLER'S ASPECTUAL VERB CLASSIFICATION (VENDLER, 1967)

\begin{tabular}{|l|l|l|}
\hline & VENDLER'S ASPECTUAL VERB CLASSIFICATION (VENDLER, 1967) \\
\hline+ endpoint & Accomplishment & Achievement \\
\hline - endpoint & Activity & State \\
\hline
\end{tabular}

According to Vendler, while states correspond to non-continuous tenses without an endpoint, activities associate with continuous tenses without an endpoint. On the other hand, both achievements and accomplishments are associated with an endpoint, but only accomplishments denote continues tenses while achievements do not.

\section{LITERATURE REVIEW}

\section{A. Stative Verbs}

The use of stative verbs in progressive forms in English has been commonly recognized as ill formed and almost infrequent (Comrie 1981; Quirk et al., 1972). Progressive statives have been considered as unacceptable due to their semantics and they have been deemed as independent of context (Smiecinska, 2002). Progressive aspect implies a typical durative situation which is expressed as progressing through time with an internal temporal structure (Collins, 2008). Kaietel (1997) suggested that different structures with state verbs can be acceptable as long as context is taken into account. Progressive aspect has traditionally been associated with the semantic of the verb, it expresses a duration which is not common to be used with state verbs in comparison with action verbs. Comrie (1976); Lakoff (1970); Leech (1971) are among those who consider the progressive form unacceptable with state verbs, however they also make lists of exceptions i.e. the statives which can appear in progressive forms. Kakietek (1997) argues that statives are not separate categories with which progressive form is unacceptable rather its use can be justified as acceptable depending on the context.

Smiecinska (2002) reports that Hirtle (1967) differentiated between states and actions claiming that progressive form is only acceptable with action verbs, since their lexical content is open to variation from one moment to another while in states every instant involves the same lexical content (cited in Smiecinska, 2002). Comrie (1976), Joos (1964), Ota (1963), among others also argue that certain lexemes express unlimited duration and are rarely used in the progressive. Hence, Smiecinska (2002) concluded that not only the context but also the semantic content plays an important role in aspectual format. The terms status and stative are also used to refer to these verbs, the latter being probably the most common term used, among others, in Quirk et al (1972) and Comrie (1976).

In this section, the researchers who believe that statives can occur in progressive form are discussed (Cited in Kakietek, 1997). Scheffer (1975) in a corpus study of contemporary British and American novels found numerous uses of stative verbs in progressive form. Kakietek (1997) drew a similar conclusion mentioning the increasing use of the progressive, with verbs traditionally labeled as stative. He reported that stative verbs are not of a separate syntactic category. He also stated that "the overwhelming majority of statives when used under appropriate circumstances are quite free to take the progressive form and cannot be viewed as constituting a separate syntactic category". Debopam Das (2010) investigated the uses and distribution of non-progressive verbs in progressive forms in an electronic corpus (COCA). He considered the occurrence of non-progressive verbs in progressive aspect against a number of factors such as tense, VP structure, polarity, contraction type and genres. The basic observation of the study is that the conventionally recognized non-progressive verbs are not at all forbidden to occur in progressive form or that they are rather very frequent in that particular aspectual usage is in contradiction with the notions adopted by traditional grammarians. The findings were more in line with others' such as Kakietek (1997) and Smiecinska (2002). Smiecinska (2002) conducted a survey on the acceptability of progressive form in stative verbs. He examined the lists of stative verbs from Scheffer (1975), and chose 30 verbs assumed to be statives by the majority of the authors quoted by Scheffer. Based on the frequency of usage, the number was narrowed down to 14 which were used in the progressive form in a context generally assumed to be characteristic of process or dynamic verbs. He concluded that stative verbs occur in the progressive in various corpora and everyday speech does not seem sufficient to postulate a fully contextual analysis of these verbs in present day American English.

Many speakers, on the other hand, find the relevant constructions rather awkward. Thus, contrary to Kakietek's postulations, no matter how convincing a context one invents, for many native speakers the kind of the verbs used, or actually its meaning, still imposes the form of the grammatical construction in which it appears. Comrie (1976) stated that "stative verbs do not have progressive forms since this would involve an internal contradiction between the stativity of the verb and the nonstativity essential to the progressive". This idea is emphasized in Lakoff" s (1970) verb typology where the semantically stative verbs are considered to be also syntactically stative (nonactive). He assumed that stative verbs should be marked as +stative as opposed to process verbs which are -stative. Thus, the ungrammaticality of sentences such as He is knowing the answer can be ascribed to the fact that a +stative verb is used in a -stative context. 
Debopam (2010) mentioned some authors, like Hirtle (1967), Quirk et al. (1972) or Vendler (1968) who speak of stative and dynamic uses of certain verbs, rather than of stative and dynamic verbs. They claimed that any verb can have a stative or dynamic use, depending on the context and in principle there would not be a justification for distinguishing a separate class of stative verbs. Leech et al (2002) define non-progressive verbs as verbs referring to the states or actions other than something in progressive. They divide these verbs into the following four categories: (the following categories are adapted from Debopam Das, 2010).

1. Verbs of perceiving

Verbs such as feel, hear, see, smell, taste etc. constitute some members of this category since they show a physical perception. Palmer (1988) defines these verbs as "private verbs" as the speaker is the only one who is able to sense them.

2. Verbs referring to a state of mind or feeling

These verbs denote emotions, attitudes and intellectual states. Verbs such as believe, adore, desire, detest, dislike, doubt, forget, hate, imagine, know, like, love, mean, prefer, remember, suppose, understand, want, wish etc. fall under this category.

3. Verbs referring to a relationship or a state of being

These verbs refer to relationships between entities (such as belong to, concern, consist, include, involve, own, possess, represent, resemble etc.) and relationships between entities and descriptions (such as be, seem, appear etc.).

4. Verbs referring to internal sensations

Leech et al., (2002) consider these verbs to be least non-progressive, as in most cases the progressive forms are completely interchangeable with their simple counterparts. Verbs such as ache, feel, itch, hurt etc. fall under this category.

Debopam (2010) in his study considered the relative frequency of each verb types in progressive form: Group $2>$ Group $1>$ Group $4>$ Group 3. In other words, the verbs of state of mind or feeling are the most frequently occurring category followed by the verbs of perceiving while the least occurring verbs are of relationship or state of being. However, the fact that verbs of internal sensations are not that frequent in progressive aspect (they stand in third position in order) contradicts Leech et al., (2002) assumption that they are the least non progressive among all categories.

\section{B. Achievement Verbs and Telicity/Duration Tests}

Achievement verbs are defined as a category which expresses an occurrence at a dingle moment. Yasuko (2005) proposed a revision of achievement verbs categories done by Dowty (1979).

A. Cognition (realized as transitive verbs): detect, find, discover, notice, perceive, recognize, spot, witness

B. Acquisition and Loss (realized as transitive verbs): acquire, get, lose, win

C. Arrival and Departure (realized as transitive/intransitive verbs): arrive, land, reach, leave, depart

D. Emergence, Appearance and Disappearance (realized as intransitive verbs): happen, occur, appear, die

E. Change of quantity (realized as intransitive verbs): increase, decrease, ascend, descend, rise, sink, fall, drop

F. Change of State (Bounded states) (realized as intransitive verbs): break, shatter, split, explode, collapse,

G. Change of State (Unbounded states) (realized as intransitive verbs): cool, warm, narrow, slim, slow, thin

The progressive uses of achievement verbs and minor differences in meaning brought about by the verb-type of achievement were discussed by Yasuko, a summary of which is proposed here.

Yasuko (2005) mentioned examples from Kearns (1991) saying that achievement verbs are generally inconsistent with the progressive as shown in (3).

(3) a. *John is noticing the hole in the floor.

b. *She is recognising the one with the moustache.

c. *He's spotting the car. (Kearns 1991, p.p. 166-167)

The reason for this inconsistency is the incompatibility of achievement verbs with the duration that the progressive requires. The progressive is possible, however, for some achievement verbs as follow:

(4) a. The train is arriving at platform.

b. The queen was dying. (Quirk et al., 1985, p. 209)

c. Jane is just reaching the summit. (Rothstein 2004, p. 43)

Progressive achievements as shown in (4) represent 'fortunate (Dowty 1979) and require what Caudal and Roussarie (2000, p. 362) call "prospective reading" i.e. the progressive is possible where the utterance is close to the goal point and the realization of the attainment is anticipatory enough. In the examples of $(4 a-c)$, the arrival of the train, the queen's death, and Jane's reaching of the summit, respectively, must be expected as a plausible event in an immediate future.

Yasuko discussed in detail whether each of the subcategories of achievement verbs is compatible with progressive form or not.

She stated that Group (A) Cognition and (B) acquisition/loss verbs resist the progressive because the punctual event expressed by the verb does not coincide with the duration that the progressive presupposes.

(5) a. *John is noticing the hole in the floor. 
The progressives of win, find, die, (group $C$ ) and arrival/departure verbs are possible only when the subject almost reaches the final goal and is about to reach the ending point

(6) a. Flight 246 is now arriving at Gate 20.

If the context is in violation of this 'prospective reading' (cf. Caudal and Roussarie 2000, p. 362), the progressive is unacceptable.

(7) a. *Mary was reaching the top of the mountain when she had to take refuge from an avalanche. So she didn't make it that time. (cf. Rothstein 2004: 56)

(7a) is unacceptable because the subject, Mary, actually didn't attain the goal (Vlach 1981, p. 280).

Group (D) and (F)

Emergence (D) and appearance/disappearance verbs (F) naturally occur in the progressive.

(8) a. What's happening?

Group $(\mathrm{E})$ and $(\mathrm{G})$ telic and atelic

The verbs in Group (E) and (G) have no problem with the occurrence in the progressive.

(9) a. The inflation is rising rapidly. (COB)

(10) a. His body chilled to the bone was gradually warming as he took a rest beside the fire.

\section{Purpose And Research Question}

In this study, the L2 learners' of English as well as native speakers' judgment on achievement and state verbs are investigated. Students are assessed if they have acquired the fact that these categories are not used in durative forms in certain contexts. (Activities and accomplishment are excluded because there is not much difference with regard to aspect between English and Persian).

\section{Research Questions and Hypotheses}

The present study is an attempt to answer the following questions and null hypotheses:

1. How well do Persian learners of English acquire aspect in state verbs comparing with English native speakers?

2. How well do Persian learners of English acquire aspect in achievement verbs comparing with English native speakers?

Based on these research questions, the following hypotheses were form:

H1. Persian learners of English do not acquire aspect in achievement verbs to native level.

H2. Persian learners of English do not acquire aspect in state verbs to native level.

Despite the fact that linguistically speaking state and achievement verbs are considered as incompatible with progressive form, many verbs from this category can be seen in progressive form. Therefore, this study reports on the judgment of both native English speakers and EFL learners of English.

The finding of this study can boost our understanding of different stages of acquisition of aspect (where differences exists between Persian and English), and whether advanced learners' judgment is close to that of the native speakers. Investigation into how interlanguage develops and what factors contribute to the learners' language progress is needed for a comprehensive understanding of the mechanism of L2 acquisition (Carroll, 1999 a. b; Gregg, 1996; Klein \& Martohardjono, 1999).

\section{METHOD}

\section{A. Participants}

The population from which the participants were selected included the students of Iran Language Institute (Isfahan branch) who had enrolled in English classes in winter semester in 2011. The ILI courses are composed of 18 levels which are made of six main proficiency levels i.e. basic, elementary, pre-intermediate, intermediate, upper intermediate, and advanced. There are three separate levels in each one of the main proficiency levels which make a total of 18 levels. Levels, 6, 12, 18 i.e. Elementary 3, Intermediate 3, and advanced 3 respectively were chosen for the placement test. The rationale behind choosing elementary 3 as the initial level for the prospective participants was a pilot study and OPT (Oxford Placement Test) which was administered a month before the study. Participants were told that the results of the study are for educational purposes and were asked to write their names so that they would take the tests seriously. The test was taken in the presence of the researcher and the class teacher. Participants were both male and female whose ages ranged from 15 to 25 . Even though the students were studying in the levels titled elementary, intermediate, and advanced, to confirm the homogeneity and to determine the proficiency level, an OPT (Oxford Placement Test) had been administered before the study was carried out. Out of a 120 student population, 100 were chosen for the study and this number was later narrowed down to 80, by excluding the ones who filled the questionnaires carelessly or not completely. The careless test takers were identified by insertion of a repeated item or the ones who had not answered the tests completely.

Having administered the OPT, the researcher divided the participant into three proficiency groups: elementary $(\mathrm{N}=20)$ those who scored (18-29), lower intermediate $(\mathrm{N}=20)$ OPT scores of (30-39), upper intermediate $(\mathrm{N}=20) \mathrm{OPT}$ range scores of (40-47) and advanced $(\mathrm{N}=10)$ within 55-60. The advanced learners were English language teachers who held 
Master's degree in TEFL. All of the students took the questionnaires regardless of the OPT results; nevertheless, papers of heterogeneous ones were discarded and not included in the study.

Ten English native speakers living in London, age ranges of 21-30, working at Accura Partners LLP, and who held Bachelor's Degree were asked to participate in this study.

\section{B. Material}

Eight stative verbs including: like, think, know, understand, hate, believe, cost, doubt were chosen for the purposes of this study. The verb "understand" was repeated in a different context, to check the testing effect. Smiecinska (2003) examined the list of stative verbs from Scheffer (1975) and chose a sample of around thirty verbs assumed to be statives by majority of authors. Smiecinska further narrowed it down to the total of 14 verbs, based on their frequency in Brown Corpus and Collins Cobuild Corpus of spoken English. Eight out of these 14 verbs which were determined as unacceptable in progressive form by more than 50 percent of the 30 native speakers in Smiecinska's study were chosen for this study. Each verb was used in a sentence with a context generally assumed to be characteristic of dynamic or process verbs. All of the verbs were used in progressive form and the participants were asked to determine whether the sentences were grammatically correct or not. Provided that they found it incorrect, they were asked to modify the sentence in a way that is sounded grammatically acceptable. The sentences were devised in a way that the literal translation in Persian would lead to an acceptable sentence.

This test not only included stative verbs in progressive form but also ten achievement verbs including: discover, recognize, find, win, reach, achieve, notice, spot, arrive and lose. Yasuko (2005) revised the categories of achievement verbs made by Dowty (1979) and introduced six categories which were introduced in the review of literature. These verbs are thought to express an occurrence at a single moment and it is widely accepted in the literature that achievement verbs express punctual events i.e. an event that occurs at a single moment, as so incompatible with progressive form (smith, 1991; Tenny, 1992; Beavers, 2002) and are characterized as the featural opposition [+telic, stage] in Rothstein (2004). Yasuko stated that among the six categories, two i.e. cognition and acquisition/loss verbs resist progressive and that is because of the fact that the punctual event expressed by these verbs does not coincide with duration that the progressive presupposes. She argued that arrival/departure verbs are possible only when the subject almost reaches the final goal of the act and the attainment of the act can be anticipatory enough in the situation and if the context is in violation of this "prospective reading" (cf Caudal \& Roussarie, 2000), the progressive is unacceptable, as so, the arrival verbs used in the questionnaire cannot be used in progressive form due to the fact that the context is devised in a form that the prospective reading is violated. Consequently all the contexts in this questionnaire are devised in a way that the prospective reading (Yasuko, 2005) is violated and based on the study done by Rothstein (2004) and Vlach (1981) can be considered as ungrammatical. All the progressive forms which were anticipated to be unacceptable by native speaker, if literally translated into Persian, were grammatically correct. The questionnaire also included 9 fillers or distracters, Sentences 2, 5, 7, 10, 14, 17, 21, 24, 27. Sentences 2, 7, 20 and 21 all displayed a misuse of preposition. Sentences 5 and 14 involved misuse of the adverb "gradually". Sentence 17 included the structure "rather that" instead of "rather than" and in sentence 27 double negation occurred. The participants were asked to circle $(\sqrt{ })$ if they felt the sentence is grammatically acceptable and $(*)$ if they thought of the sentence as grammatically incorrect and (?) in case they were not sure whether the sentence sounded correct or not. For all the unacceptable sentences, they were asked to underline the erroneous part and write the correct form. All the instructions were given in participants' native language and they were provided with an example. The example and instruction were read by the researcher and if the students had any problems considering the questionnaire they were allowed to ask.

\section{Procedure}

The grammaticality judgment of stative and achievement verbs was made of 29 items, fillers included. The participants had almost 30 seconds for each item which enabled them to read the item at least 4 times. This time was calculated after asking ten elementary students to read the item aloud, slow enough to understand the meaning. This part took a total of 15 minutes. The participants were not allowed to go back through the questions and each page of the questionnaire included on question so that the participants could not compare and change their answers.

\section{Data Analyses}

All of the questionnaires were graded by the researcher and an assistant. Each item was either grated as correct that is 1 and incorrect i.e. 0.

To address the research questions, SPSS (Statistical Package for Social Sciences) Version 16.0 was used to perform all the statistical analyses in this study.

A number of statistical analyses were conducted; firstly, the mean score of each level in each test was calculated. Then, ANOVA was run on each dependant variable to see whether there were any statistically significant differences across the groups. Lastly, Pos hoc scheffe was carried out to locate the significant factor.

\section{RESULTS}

\section{A. State and Achievement Verbs}


This sections deals with results from all of the five groups on their judgment of progressive aspect on achievement as well stative verbs. The mean scores of each group's performance on these two kinds of verbs are compared in Fig. 1. In all groups, the participants performed superior on state verbs comparing with achievement verbs.

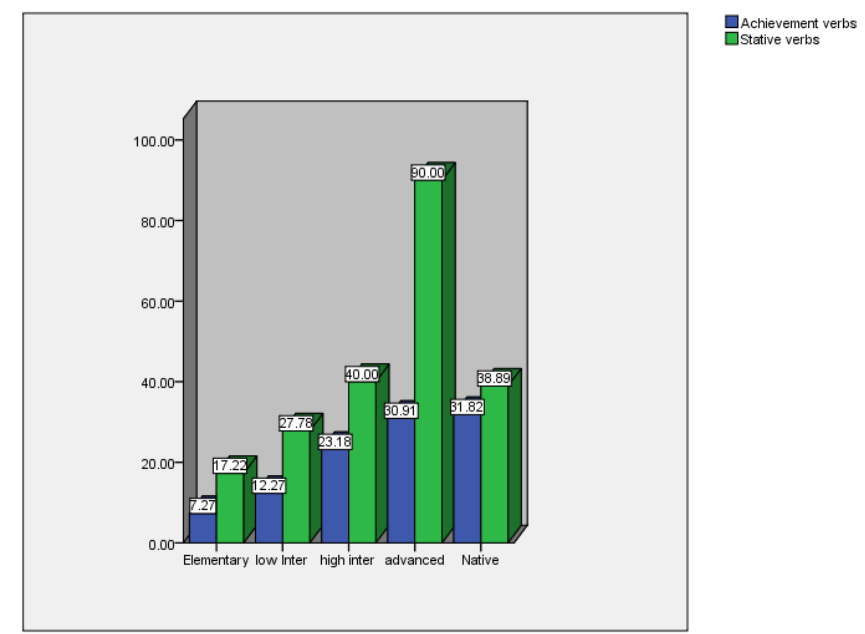

Fig. 1. Mean scores of different groups on stative and achievement verbs

The mean score on stative verbs gradually increased from elementary to high intermediate; nevertheless, there is a dramatic increase in advanced level with a mean score of 90 percent which is 50 percent higher that high intermediate level. What makes the result very interesting is the fact that native speakers did not perform even as well as high intermediate participants, though the numerical difference is marginal and not significant. In achievement verbs, the increase is gradual, that is, the higher the level of the participants is, the higher the mean score on the test is.

ANOVA results in Table 5. proves the fact that the differences in performance of the groups is significant for both state $(\mathrm{F}=7.152, \mathrm{P}=.000)$ and achievement verbs $(\mathrm{F}=16.219, \mathrm{P}=.000)$.

TABLE 5.

ANNOVA RESULTS FOR STATIVE AND ACHIEVEMENT VERBS

\begin{tabular}{|c|c|c|c|c|c|c|}
\hline & & Sum of Squares & df & Mean Square & $F$ & Sig. \\
\hline $\begin{array}{l}\text { Grammaticaly judgment } \\
\text { achievement verbs }\end{array}$ & $\begin{array}{l}\text { Between Groups } \\
\text { Within Groups } \\
\text { Total }\end{array}$ & $\begin{array}{l}7048.554 \\
18479.339 \\
25527.893\end{array}$ & $\begin{array}{l}4 \\
75 \\
79\end{array}$ & $\begin{array}{l}1762.138 \\
246.391\end{array}$ & 7.152 & .000 \\
\hline $\begin{array}{l}\text { Grammaticaly judgment Stative } \\
\text { verbs }\end{array}$ & $\begin{array}{l}\text { Between Groups } \\
\text { Within Groups } \\
\text { Total }\end{array}$ & $\begin{array}{l}37819.444 \\
43722.222 \\
81541.667\end{array}$ & $\begin{array}{l}4 \\
75 \\
79\end{array}$ & $\begin{array}{l}9454.861 \\
582.963\end{array}$ & 16.219 & .000 \\
\hline
\end{tabular}

Post hoc was run (Table 6) to locate the differences between the different levels. 
TABLE 6.

POST HOC RESULTS FOR STATE AND ACHIEVEMENT VERBS

\begin{tabular}{|c|c|c|c|c|c|c|c|}
\hline \multirow[b]{2}{*}{ Dependent Variable } & \multirow[b]{2}{*}{ (I) Level } & \multirow[b]{2}{*}{ (J) Level } & \multirow[b]{2}{*}{ Mean Difference (I-J) } & \multirow[b]{2}{*}{ Std. Error } & \multirow[b]{2}{*}{ Sig. } & \multicolumn{2}{|c|}{$95 \%$ Confidence Interval } \\
\hline & & & & & & Lower Bound & Upper Bound \\
\hline \multirow{20}{*}{$\begin{array}{l}\text { Grammaticaly judgment } \\
\text { achievement verbs }\end{array}$} & \multirow[t]{4}{*}{ Elementary } & low Inter & -5.00000 & 4.96378 & .907 & -20.6770 & 10.6770 \\
\hline & & high inter & $-15.90909^{*}$ & 4.96378 & .045 & -31.5861 & -.2320 \\
\hline & & advanced & $-23.63636^{*}$ & 6.07936 & .007 & -42.8367 & -4.4360 \\
\hline & & Native & $-24.54545^{*}$ & 6.07936 & .005 & -43.7458 & -5.3451 \\
\hline & \multirow[t]{4}{*}{ low Inter } & Elementary & 5.00000 & 4.96378 & .907 & -10.6770 & 20.6770 \\
\hline & & high inter & -10.90909 & 4.96378 & .315 & -26.5861 & 4.7680 \\
\hline & & advanced & -18.63636 & 6.07936 & .062 & -37.8367 & .5640 \\
\hline & & Native & $-19.54545^{*}$ & 6.07936 & .044 & -38.7458 & -.3451 \\
\hline & \multirow[t]{4}{*}{ high inter } & Elementary & $15.90909 *$ & 4.96378 & .045 & .2320 & 31.5861 \\
\hline & & low Inter & 10.90909 & 4.96378 & .315 & -4.7680 & 26.5861 \\
\hline & & advanced & -7.72727 & 6.07936 & .805 & -26.9277 & 11.4731 \\
\hline & & Native & -8.63636 & 6.07936 & .732 & -27.8367 & 10.5640 \\
\hline & \multirow[t]{4}{*}{ Advanced } & Elementary & $23.63636^{*}$ & 6.07936 & .007 & 4.4360 & 42.8367 \\
\hline & & low Inter & 18.63636 & 6.07936 & .062 & -.5640 & 37.8367 \\
\hline & & high inter & 7.72727 & 6.07936 & .805 & -11.4731 & 26.9277 \\
\hline & & Native & -.90909 & 7.01985 & 1.000 & -23.0798 & 21.2616 \\
\hline & \multirow[t]{4}{*}{ Native } & Elementary & $24.54545^{*}$ & 6.07936 & .005 & 5.3451 & 43.7458 \\
\hline & & low Inter & $19.54545^{*}$ & 6.07936 & .044 & .3451 & 38.7458 \\
\hline & & high inter & 8.63636 & 6.07936 & .732 & -10.5640 & 27.8367 \\
\hline & & advanced & .90909 & 7.01985 & 1.000 & -21.2616 & 23.0798 \\
\hline \multirow{20}{*}{$\begin{array}{l}\text { Grammaticaly judgment } \\
\text { Stative verbs }\end{array}$} & \multirow[t]{4}{*}{ Elementary } & low Inter & -10.55556 & 7.63520 & .752 & -34.6697 & 13.5586 \\
\hline & & high inter & -22.77778 & 7.63520 & .074 & -46.8919 & 1.3364 \\
\hline & & advanced & $-72.77778^{*}$ & 9.35117 & .000 & -102.3115 & -43.2441 \\
\hline & & Native & -21.66667 & 9.35117 & .262 & -51.2004 & 7.8670 \\
\hline & \multirow[t]{4}{*}{ low Inter } & Elementary & 10.55556 & 7.63520 & .752 & -13.5586 & 34.6697 \\
\hline & & high inter & -12.22222 & 7.63520 & .635 & -36.3364 & 11.8919 \\
\hline & & advanced & $-62.22222^{*}$ & 9.35117 & .000 & -91.7559 & -32.6885 \\
\hline & & Native & -11.11111 & 9.35117 & .841 & -40.6448 & 18.4226 \\
\hline & \multirow[t]{4}{*}{ high inter } & Elementary & 22.77778 & 7.63520 & .074 & -1.3364 & 46.8919 \\
\hline & & low Inter & 12.22222 & 7.63520 & .635 & -11.8919 & 36.3364 \\
\hline & & advanced & $-50.00000^{*}$ & 9.35117 & .000 & -79.5337 & -20.4663 \\
\hline & & Native & 1.11111 & 9.35117 & 1.000 & -28.4226 & 30.6448 \\
\hline & \multirow[t]{4}{*}{ advanced } & Elementary & 72.77778* & 9.35117 & .000 & 43.2441 & 102.3115 \\
\hline & & low Inter & $62.22222^{*}$ & 9.35117 & .000 & 32.6885 & 91.7559 \\
\hline & & high inter & $50.00000 *$ & 9.35117 & .000 & 20.4663 & 79.5337 \\
\hline & & Native & $51.11111^{*}$ & 10.79780 & .001 & 17.0085 & 85.2137 \\
\hline & \multirow[t]{4}{*}{ Native } & Elementary & 21.66667 & 9.35117 & .262 & -7.8670 & 51.2004 \\
\hline & & low Inter & 11.11111 & 9.35117 & .841 & -18.4226 & 40.6448 \\
\hline & & high inter & -1.11111 & 9.35117 & 1.000 & -30.6448 & 28.4226 \\
\hline & & advanced & $-51.11111^{*}$ & 10.79780 & .001 & -85.2137 & -17.0085 \\
\hline
\end{tabular}

*. The mean difference is significant at the 0.05 level.

The results of post hoc revealed that with regards to achievement verbs there were significant differences between elementary with high-intermediate, advanced and native speakers and the low-intermediate participants differed significantly with native speakers only.

In state verbs, advanced participants differed significantly with all groups, native speakers included. The reason can be contributed to fact that advanced learners of English are exposed to explicit rules of prescriptive grammar. In different grammar books, they have studied state verbs (comparing with action verbs) are not used in progressive form while native speaker use their intuition to mark the progressive form of stative verbs as either acceptable or 
unacceptable. Accordingly both hypotheses are rejected since Iranian learners of English acquire the aspect in achievement and stative verbs.

What follows are two figures representing the participants' performance on each verb of stative and achievement category. As can be seen, some verbs are not accepted as acceptable in progressive form more than the others.
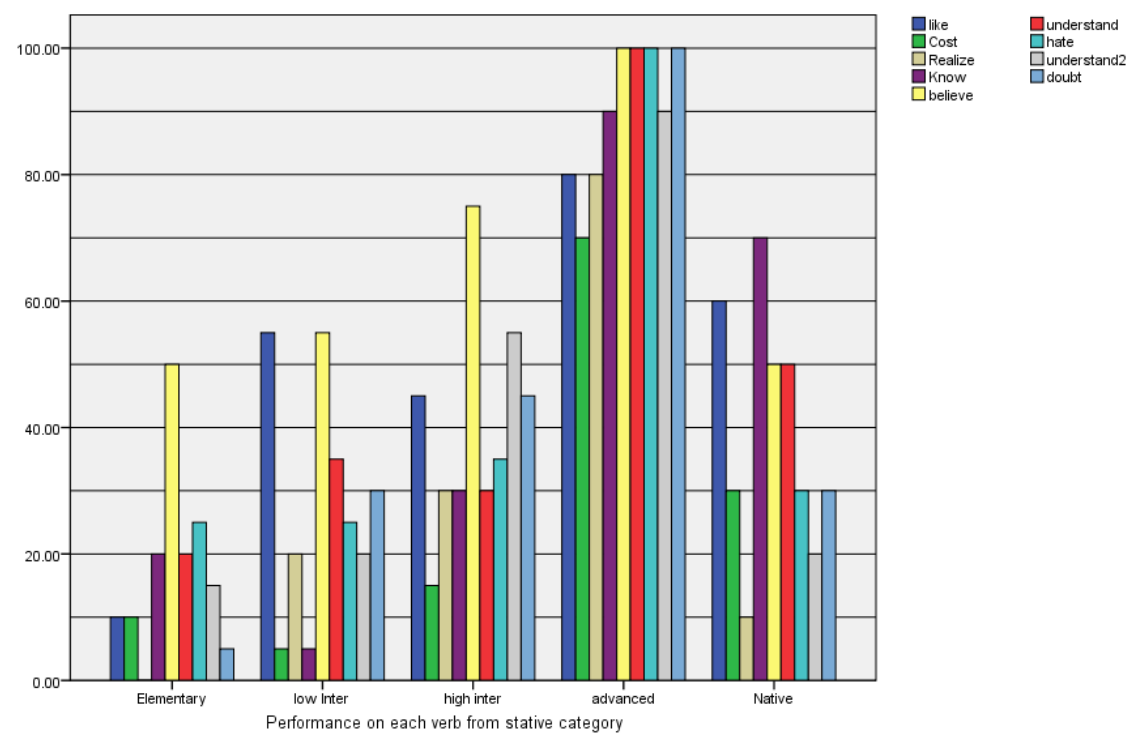

Fig, 2, Mean scores on each verb of stative verbs
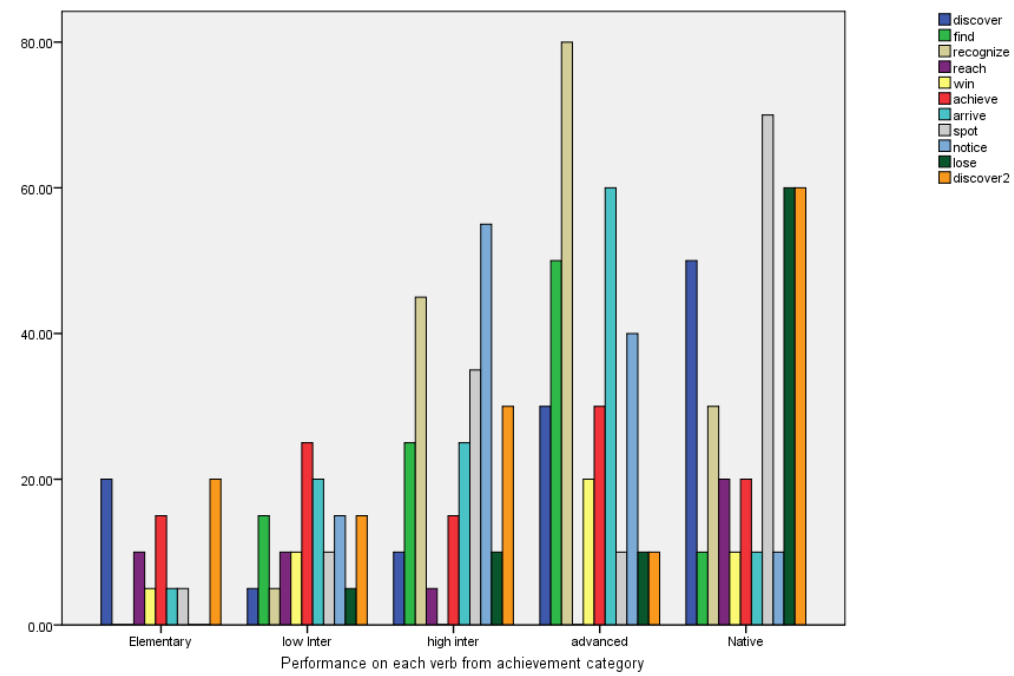

Fig. 3, Mean scores on each verb of achievement verbs

\section{B. Summary of the Results}

The results for stative verbs was unpredictable since advanced participants considered progressive forms unacceptable with a high margin comparing with even native speakers, showing the fact that they follow the rules in prescriptive grammar which states that stative verbs cannot be used in progressive form. While native speakers considered the usages in most cases acceptable. As so, hypotheses 1, was rejected; Persian learners of English have acquired the aspect in stative verbs.

The results of achievement verbs showed that in all groups, even native speakers, the majority did not consider progressive use of achievement verbs as unacceptable. However the numerical differences between native and advanced participant was marginal which led to the rejection of the second hypotheses and proving the fact that the advanced participant can perform as accurately as the native speakers do.

\section{DISCUSSION, CONCLUSION AND IMPLICATIONS}

\section{A. Progressive Forms in Stative Verbs}


The first research question dealt with the fact if native and non native learners of English consider progressive form in stative and achievement verbs as acceptable or not. Very interesting results were found; more advanced learners considered progressive use in stative verbs unacceptable than the native speakers did. In fact the difference was significant. To account for this finding, first some points on the use of progressive form in stative verbs should be discussed. As mentioned, the use of stative verbs in progressive forms in English has been commonly recognized as exceptional and rather infrequent (Comrie 1976, 1981; Quirk et al.1972; Lakoff 1970; Leech 1971). Progressive statives have been considered as unacceptable due to their semantics and they have been deemed as independent of context (Smecink 2002; Collins, 2008). Comrie (1973), Joos (1964), Ota (1963), among others argued that certain lexemes express unlimited duration and are hardly ever used in the progressive. Comrie (1976) stated that "stative verbs do not have progressive forms since this would involve an internal contradiction between the stativity of the verb and the nonstativity essential to the progressive". This idea is emphasized in Lakoff" s (1970) verb typology where the semantically stative verbs are considered to be also syntactically stative (nonactive). He assumed that stative verbs should be marked as +stative as opposed to process verbs which are -stative. Thus, the ungrammaticality of sentences such as $H e$ is knowing the answer can be ascribed to the fact that a +stative verb is used in a -stative context. Considering claims made by the aforementioned researchers, the test was designed. The results revealed that the advanced learners considered the progressive usage as unacceptable. The reason why advanced and high intermediate groups considered the progressive usage as ungrammatical resorts from the fact that they study the prescriptive grammar which explicitly dictates some forms of usage. Most popular grammar books, the ILI text book included, reject the progressive usage of state verbs. Consequently, due to studying the rules for usage, advanced learners find these examples erroneous. Nevertheless, the native speakers resort to their intuition of their native language to judge the sentences as either grammatical or ungrammatical.

On the other hand, in the literature, it is found that statives, in certain contexts, can occur in progressive form (Kakietek 1997; Smiecinska (2003) Scheffer (1975 Debopam Das (2009). Scheffer (1975) in a corpus study of contemporary British and American novels found uses of stative verbs in progressive form. Kakietek (1997) drew a similar conclusion mentioning the increasing use of the progressive, with verbs traditionally labeled as stative. He showed that stative verbs do not constitute a separate syntactic category suggesting that different structure with stative verbs are acceptable as long as context is taken into consideration. Debopam Das (2010) investigating the uses and distribution of non-progressive verbs in progressive forms in an electronic corpus (COCA) found that the conventionally recognized non-progressive verbs are not at all forbidden to occur in progressive form or that they are rather very frequent in that particular aspectual usage is in contradiction with the notions adopted by traditional grammarians. The results of this study are in line with the studies mentioned in this part i.e. despite the fact that all the verbs and context were devised in a form that the progressive of which was considered as unacceptable by the opponents of this usage (Comrie 1976, 1981; Quirk et al.1972; Lakoff 1970; Leech 1971) the native speakers showed a different picture. To put it in other words, they considered most of the usages as acceptable.

\section{B. Progressive Forms in Achievement Verbs}

It is generally assumed that achievement verbs are inconsistent with the progressive (Kearns 1991: 166-167). The traditional account for this phenomenon is that the punctuality of achievement verbs is incompatible with the duration that the progressive requires. The progressive is possible, however, for some achievement verbs (Quirk et al. 1985), (Rothstein 2004). As mentioned, some sub categories of achievement verb resist progressive form regardless of the context in which they are used.

As for the present study, almost $70 \%$ of participants in all groups considered the progressive form of achievement verbs acceptable, while only $10 \%$ of advanced learners marked continuous stative verbs as compatible. The explanation for this difference can be sought in the learners L1. In Farsi, the progressive form sound rather natural and the only factor making advanced learners mark progressive stative verbs as ill formed is the grammatical rules they have studied. However, when it comes to achievement verbs, since they are not as explicitly rejected with progressive forms as stative verbs are in different grammar books, they resort to their L1, hence, it sound rather natural to them.

\section{Conclusion}

Based on the results reported and the discussion conducted in the previous sections, several conclusions can be drawn.

First of all, the results for stative verbs revealed that, surprisingly, more advanced participants considered progressive forms unacceptable comparing with even native speakers, showing the fact that they follow the rules in prescriptive grammar which states that stative verbs cannot be used in progressive form, while native speakers considered the usages in most cases acceptable.

Secondly, in all groups, even native speakers, the majority did not consider progressive use of achievement verbs as unacceptable and numerically, the difference between native and advanced participant was not marginal, proving the fact that the advanced participant performed closely to the native speakers. In Farsi, the progressive use in achievement verbs and state verbs is rather acceptable and natural. Most English grammar books reject this usage with state verbs and not achievement verbs, thus, when it comes to state verbs, the learners report that progressive usage is ill formed. For achievement verbs, however, since they do not study any explicit rules, they resort to their L1 and since in Farsi it is acceptable, the majority marks them as acceptable. 


\section{Implications of the Study}

With regards to aspect in state and achievement verbs, the teachers need to be more cautious when claiming that these verbs cannot be used in progressive form, a fact that is mentioned in many grammar books they study or teach. Being a verb of these categories does not necessarily mean that they cannot be used in progressive form, even if they are linguistically deemed as incorrect. As was shown in the present study, the native speakers considered many of the progressive usage acceptable, especially in achievement verbs.

Material developers, especially those writing grammar books, are expected to consider the fact that the native speakers do accept the progressive form in achievement and stative verbs and they cannot strongly prescribe that the usage is unacceptable because the only trustworthy materials for learners as well as teachers in foreign language context are the grammar books. As seen in the present study, more advanced non native speakers of English considered the usage as ungrammatical comparing with the native speakers of English proving the fact that they are influenced by the prescriptive grammar. This claim is made since if the advanced participants had resorted to their L1, they would have marked the usage as acceptable, as it is the case in Farsi.

\section{E. Limitations of the Study}

This study faced a number of limitations which will be discussed briefly.

Firstly, there was no access to a sufficient number of native speakers of English. Having sought many native speakers cooperation, no more than 10 native speakers answered the questionnaires which are not enough for a comprehensive conclusion to be drawn.

Secondly, to count for the problem of careless answering, the researcher conducted two measures. First, one of the questions in the questionnaire was exactly repeated after almost 20 items to detect the careless and unwilling participants. Another thing was to ask participant to correct the parts that they had marked as incorrect. The papers which had a problem in any of these two aspects were drop out of the study. Despite these measures, some errors might have crawled because the participants might have answered some of them carelessly.

The third issue is the matter of learning or test effect that might have occurred. Because of the number of questions, the participants might have gotten cognizant of the issue tested and changed their answers after recognizing one of the items. To counter this problem, each question was in one page of a pamphlet and the participants were not allowed to change their answers once they moved to next page or to go through the previous pages. If the researcher had access to OHP it might have been more accurate.

Fourthly, the number of participants in advanced level was not enough, that is because of the fact that the advanced participants were chosen among a population who were graduate students of English and had scored 50 and above on OPT, as so, no more than 10 participants were legitimate for this study.

\section{F. Suggestions for Further Research}

Having conducted this study in the area of second language acquisition, the researcher discovered some potential avenues for further research:

1. Using a variety of verbs from state and achievement category in different contexts with a large population of participants will enrich our understanding of the natives' intuition on the use of progressive form with the mentioned types of verb.

2. Increasing the numbers of native speakers and choosing from educated and less educated people both in England and America or other English speaking countries can help the researchers draw a comprehensive conclusion. A corpus study can be of value if a large number of verbs from the same category are examined.

\section{ACKNOWLEDGMENT}

The authors are grateful to the Office of Graduate Studies at the University of Isfahan for their support.

\section{REFERENCES}

[1] Beavers, J. (2002). Aspect and the distribution of prepositional resultative phrases in English. Unpublished ms, Stanford University, Stanford, CA.

[2] Caudal, P. \& L. Roussarie. (2000). "Event Structure vs. Stage Structure and Abstract Aspectual Relations", in Proceedings of the 26th Meeting of the Berkeley Linguistics Society (BLS'26), U.C. Berkeley, CA.

[3] Carroll, S. (1999a). Adults' sensitivity to different sorts of input. Language Learning, 49 (1), 37-92.

[4] Carroll, S. (1999b). Putting 'input' in its proper place. Second Language Research, 15 (4), 337-388.

[5] Chung, S. \& Timberlake, A. (1985). Tense, aspect, and mood. In T. Schopen (Ed.). Language Typology and Syntactic Description, vol. III. Grammatical categories and the lexicon. Cambridge: Cambridge University Press.

[6] Collins, P. (2008). The Progressive Aspect in World Englishes: A Corpus-based Study. Australian Journal of Linguistics, 28 (2), $225-249$.

[7] Comrie, B. (1976). Aspect. Cambridge, Cambridge University Press.

[8] Comrie, B. (1981). Language universals and linguistic typology: Syntax and morphology. Chicago: University of Chicago Press. 
[9] Debopam, D. (2010). The Uses and Distribution of Non-Progressive Verbs in Progressive Forms: A Corpus-based Study.26th Northwest Linguistics Conference, Vancouver, May 8-9.

[10] Dowty, D. R. (1979). Word meaning and Montague grammar. Dordrecht: Reidel.

[11] Gabriele, A. (2005). The acquisition of aspect in a second language: a bidirectional study of learners of English and Japanese. Unpublished doctoral dissertation. The city University of New York, New York.

[12] Gregg, K. (1996). The logical and developmental problem of second language acquisition. In W. Ritchie and T. Bhatia (eds.), Handbook of second language acquisition. San Diego: Academic Press.

[13] Hirtle, W. (1967). The simple and the progressive forms. Quebeck: Les press de Universite Laval.

[14] Joos, M. (1964). The English Verb. Madison and Milwaukee: The University of Wisconsin Press.

[15] Kakietek, P. (1997). The syntax and semantics of English stative verbs. Warszawa: Energia.

[16] Kearns, K. S. (1991). The Semantics of the English Progressive. PhD thesis, MIT.

[17] Klein, E., \& Martohardjono, G. (1999). Investigating second language grammars: Some conceptual and methodological issues in generative SLA research.In E. Klein and G. Martohardjono. (Eds). The development of second language grammars: A generative approach. Amsterdam: John Benjamins.

[18] Lakoff, G. (1970). Irregularity in Syntax. New York: Holt, Reinhart - Winston.

[19] Leech, G. (1971). Meaning and the English Verb. Harlow: Pearson Education Limited.

[20] Leech, G. \& Svartvik, J. (2002). A Communicative Grammar of English. London: Longman

[21] Ota, A. (1963). Tense and aspect in present day American English. Tokyo: Kenkyusha.

[22] Palmer, F. R. (1988). The English Verb.2nd Edition. London and New York: Longman.

[23] Quirk, R., Greenbaum, S., Leech, G., \& Svartvik, J. (1972). A Grammar of Contemporary English. London: Longman.

[24] Rothstein, S. (2004). Structuring Events. Oxford: Blackwell Publishing.

[25] Scheffer, J (1975). The progressive in English. Amsterdam: North Holland.

[26] Smiecinska, J. (2002). Stative Verbs and the Progressive Aspect in English. Paznan Studies in Contemporary Linguistics 38, 187-195.

[27] Smith, C. (1991).The Parameter of Aspect. Dordrecht: Kluwer.

[28] Tenny, C. (1992). The aspectual interface hypothesis. Stanford, CA: CSLI Publications.

[29] Vendler, Z. (1967). Verbs and times.In Z. Vendler (Ed.), Linguistics in Philosophy. Ithaca: Cornell University Press.

[30] Verkuyl, H. (1993). A theory of aspectuality: the interaction between temporal and atemporal structure. Cambridge: Cambridge University Press.

[31] Vlach, F. (1981). The semantics of the progressive. New York: Academic Press.

[32] Yasuko, T. (2005). Achievement Verbs and the Progressive Meanings. Journal of Osaka Sangyo University Humanities 117, 41-54

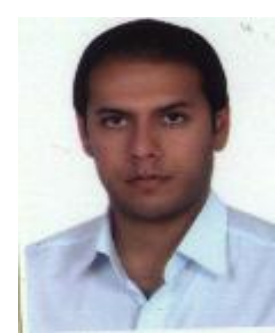

Mohammad Falhasiri was born in Kuwait in 1985. He received his Bachelor's degree in English Language Translation from Shiraz Azad University in Iran and did his M.A in TEFL at University of Isfahan in the same country.

He has 6 years of experience as English teacher in different Language Institutes and is an IELTS/TOEFL instructor at Isfahan University. For the last 3 years, he has also been a teacher trainer. He has published a number of articles and has two books in press and has also presented some papers in both local and international conferences.

Manijeh Youhanaee holds a PhD in language and linguistics from the University of Essex. She has co-authored with Badrizadeh “A Descriptive Dictionary of Theories of Generative Grammar". She has published a number of articles on the teaching/ acquisition of different English syntactic properties by native speakers of Persian. She teaches MA and PhD courses in linguistics, generative grammar, TEFL and SLA. Her areas of interest include syntactic theory, acquisition of L2 \& L3 syntax and issues in teaching and learning English as a second/foreign language.

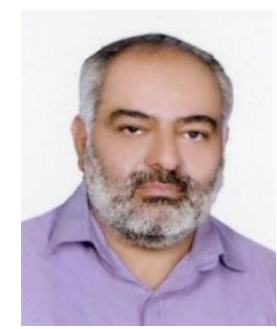

latest publications.

$\mathrm{He}$ is currently working on "New plans for Teaching English to Iranian adult non-majors", "Teaching English to Iranian young learners" and "The consequential validity of high stakes tests in the Iranian context".

Hossein Barati works in the English department, University of Isfahan, where he is assistant Professor of Applied Linguistics. He has a PhD in Language Testing from University of Bristol, England and has been involved in research in language testing, program evaluation, reading strategies, and classroom discourse. He has published in areas of language testing and assessment, and language program evaluation. He is a member of a research project on Developing a new model of teaching to adult English non-majors at University of Isfahan, funded by University of Isfahan.

He has also co-authored some publications on DIF in Iranian National University Entrance Exam (INUEE), 2007; Linguistic constraints and language teaching, 2008; and Cultural differences in EFL performance on cloze tests, 2010. Further a text-book "A step forward in English for intermediate EFL learners" is among his 